\title{
Mobile-assisted language learning through learning analytics for self-regulated learning (MALLAS): A conceptual framework
}

\author{
Olga Viberg \\ Division of Media Technology and Interaction Design, KTH Royal Institute of Technology, Sweden
}

Barbara Wasson

Centre for the Science of Learning and Technology, University of Bergen, Norway

\section{Agnes Kukulska-Hulme}

Institute of Educational Technology, The Open University, Milton Keynes, United Kingdom

\begin{abstract}
Many adult second and foreign language learners have insufficient opportunities to engage in language learning. However, their successful acquisition of a target language is critical for various reasons, including their fast integration in a host country and their smooth adaptation to new work or educational settings. This suggests that they need additional support to succeed in their second language acquisition. We argue that such support would benefit from recent advances in the fields of mobile-assisted language learning, self-regulated language learning, and learning analytics. In particular, this paper offers a conceptual framework, mobile-assisted language learning through learning analytics for self-regulated learning (MALLAS), to help learning designers support second language learners through the use of learning analytics to enable self-regulated learning. Although the MALLAS framework is presented here as an analytical tool that can be used to operationalise the support of mobileassisted language learning in a specific exemplary learning context, it would be of interest to researchers who wish to better understand and support self-regulated language learning in mobile contexts.
\end{abstract}

Implications for practice and policy:

- MALLAS is a conceptual framework that captures the dimensions of self-regulated language learning and learning analytics that are required to support mobile-assisted language learning.

- Designers of mobile-assisted language learning solutions using MALLAS will have a solution with sound theoretically underpinned solution.

- Learning designers can use MALLAS as a guide to direct their design choices regarding the development of mobile-assisted language learning apps and services.

Keywords: mobile-assisted language learning (MALL), learning analytics, self-regulated learning, data science application in education, learning design, conceptual framework

\section{Introduction}

Many adult second and foreign language (L2) learners are in need of support to acquire a target language. There can be several reasons for this, including their smoother and faster integration into a host society and successful adaptation to new educational or work settings (Uebelmesser \& Weingarten, 2017). However, a frequent obstacle for such learners is that they have insufficient opportunities to engage in language learning on their own terms, as many are in full-time jobs or enrolled in education programmes, with little spare time to participate in language classes. At least some of their language learning therefore needs to be done independently; however, knowing how to do this effectively can be challenging. Thus, additional support is critical for these learners to succeed in their L2 acquisition.

We argue that such support should focus on the development of self-regulated learning (SRL), which has been shown to positively impact academic performance (Zimmerman, 1990), learners' ability to acquire the target language successfully (Oxford, 2016; Viberg \& Andersson, 2019; Yang, 2020) and their development as lifelong learners (Yu, 2015). SRL is a complex process (Panadero, 2017). Overall, many learners possess poor SRL skills and practices, including their ability to accurately calibrate their own learning processes (Dunlosky \& Lipko, 2007). Moreover, scholars have emphasised that, without instructional support, learners may overestimate their understanding of learning materials (e.g., Baars et 
al., 2018), which might negatively influence their learning process. Given that language learners are increasingly learning the target language independently on smartphones and in online settings, there is "a growing need for understanding and intervening in these environments towards the development of SRL" (Lodge et al., 2018, p. 1). Recent advancements in the fields of mobile-assisted language learning (MALL) and learning analytics (LA) for SRL focused on measurement and support mechanisms (Winne, 2017) have shown some evidence and potential to support learners in their everyday learning practices through the use of their own mobile devices (e.g., Kukulska-Hulme \& Viberg, 2018; Shadiev et al., 2019) and their development of SRL (Lodge et al., 2018; Viberg \& Andersson, 2019; Viberg, Mavroudi, et al., 2020). Whereas the aforementioned advances are recognised in those fields separately, there have been few research attempts to draw synergies from these fields. We propose a conceptual framework, mobile-assisted language learning through learning analytics for self-regulated learning (MALLAS), which brings these advances together to support L2 learners.

MALLAS aims to aid learning designers to understand and contribute to the development of L2 learners' SRL strategies, skills and knowledge, which are critical to their successful acquisition of the L2 (Oxford, 2016). For learning designers, the framework informs their design choices for mobile technology-assisted support aimed at facilitating the acquisition of particular language skills (e.g., speaking, reading, writing). MALLAS builds on the theoretical foundations of SRL (Zimmerman, 1990), strategic self-regulated language learning (SRLL, Oxford, 2016), situated and contextual mobile learning (C. Huang et al., 2016; Kukulska-Hulme \& Bull, 2008; Lincke, 2020) and the practical and theoretical lens of LA (Bull \& Wasson, 2016; Viberg, Hatakka, et al., 2018). This paper outlines the conceptual framework and illustrates its operationalisation.

\section{Background}

\section{Mobile learning and L2 learning}

Conceptions of mobile learning (m-learning) vary according to the historical, cultural, social and educational contexts in which it is adopted and developed (Crompton, 2013). Adult L2 learners will have their own conceptions based on their experiences, and their cross-border mobility might also play a role in shaping their expectations of how they can learn. M-learning is facilitated by "enhanced mobility and flexibility that are enabled by portable devices and cloud-based networks" (Palalas \& Hoven, 2016, p. 51). It can also be conceived as "learning for mobile and connected societies" (Traxler \& Kukulska-Hulme, 2016 , p. 4), recognising that the widespread adoption of mobile technologies is transforming societies and impacting the processes of knowledge access, creation, and sharing. From this perspective, L2 learners are not only acquiring a language but also contributing to its development and diffusion, and through selfregulation they play a role in transforming language teaching and learning.

M-learning can be formal, informal or a combination; adult L2 learners may participate in some language tuition and supplement it with informal learning on their smartphones (Viberg, Andersson, et al., 2018). Informal learning, which takes place in everyday life in the family, at work, as well as in communities and "through interests and activities of individuals" (UNESCO, 2012, p. 8), affords opportunities for learning through interaction with resources encountered in these settings. However, m-learning has been criticised for its lack of focus on the examination of educational problems that "would improve learning and achieve learning goals" and its emphasis on the analysis of "things", that is, the use of computing devices (Grant, 2019 , p. 362). One key reason for this is that m-learning studies have seldom reported the underlying theoretical frameworks (Grant, 2019). We aim to fill this gap by proposing how the design of MALL can be underpinned by the theoretical lens of SRL (Oxford, 2016; Zimmerman, 1990).

MALL - a subfield of m-learning - covers a broad range of activities, including mobile access to language courses and lessons, individual practice focusing on specific skills and knowledge, collaborative and competitive language tasks and exploratory learning that exploits urban settings as informal learning environments. L2 learners may be involved in any of these activities. However, to be more successful in their L2 acquisition, they need adequate support to develop self-regulation in their learning. 


\section{L2 learning and self-regulation}

Strategic self-regulated learning (SSRL) is central to L2 acquisition (Oxford, 2011). A number of models of L2 learner self-regulation have been offered (e.g., Rubin, 2001; Scarcella \& Oxford, 1992). One of these models, Oxford's $(2011,2016)$ strategic self-regulation (S2R) model of language learning (Figures 1 \& 2), is based on Zimmerman's (1990) model of SRL and targets the metastrategies, strategies and tactics that language learners can use to regulate their learning. The S2R model covers strategies for three key constitutive dimensions of L2 learning: cognitive, affective, and sociocultural-interactive (Figure 1). Strategies in this model are dynamic; they can be learned and taught through mediation and assistance (Oxford, 2016). Cognitive strategies help the learner to construct, transform and apply L2 knowledge. Affective strategies help to create positive attitudes and keep the learner motivated. Socioculturalinteractive strategies aid the learner with communication, sociocultural context and identity.
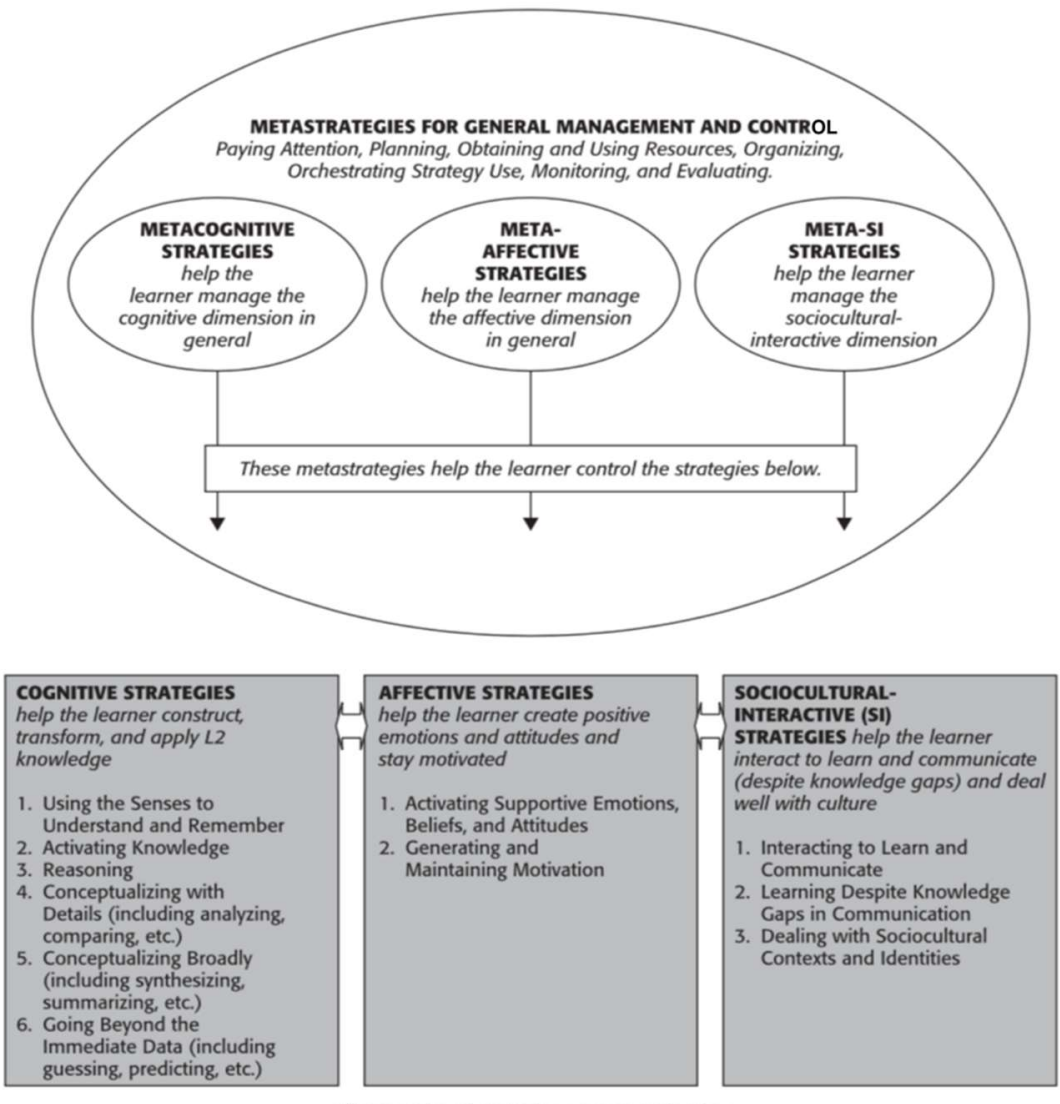

All categories of strategies support each other

Figure 1. A representation of the S2R model, emphasising metastrategies and strategies (Oxford, 2011, p. 24)

The S2R model has been employed by researchers, for example, to develop a scale for the use of selfregulated L2 learning strategies (Köksal \& Dundar, 2018), identify the types of SRL used by L2 learners (Di Carlo, 2016), as well as identify the SRL tactics employed by L2 learners of English in an academic writing course (Peeters et al., 2020). Our MALLAS framework incorporates the S2R model's three task phases (Figure 2) and provides guidance for the development of adequate mechanisms, focusing on the development and use of SRLL metastrategies, strategies, and tactics to assist L2 learners in their learning process. 


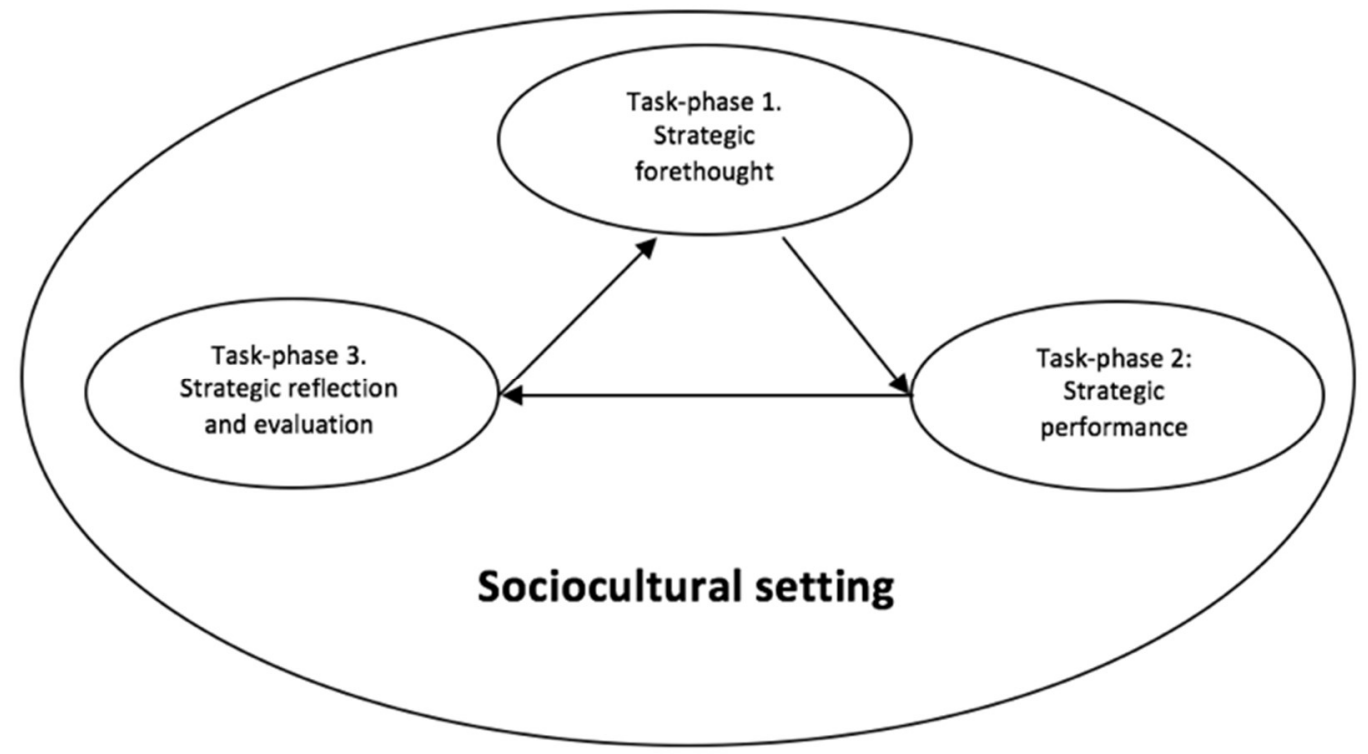

Figure 2. S2R task-phase model of language learning (Oxford, 2011, p. 25) Note. Learners do not always follow the linear order.

\section{MALL and SRL}

Research has shown that mobile technology can enhance students' L2 acquisition across formal and informal settings (Kukulska-Hulme \& Viberg, 2018). The effectiveness of mobile technology depends on human, design and institutional factors (Vogel et al., 2009). Human factors include motivation and skills in SRL activities in online learning environments (Viberg \& Andersson, 2019). Although SRL is a wellestablished research area and the learner's ability to self-regulate their language learning is critical (Oxford, 2016), research focusing on learners' self-regulation in the MALL field has been limited; few studies have addressed this issue. Yang (2020) emphasised the importance of language learners' (computer) self-efficacy - an essential part of learners' motivation - in helping them to acquire the target language more effectively. Yang also stressed that teacher mediation is critical in the earlier stages of autonomy, when learners are starting to use mobile devices for language learning. Scholars have also found that the use of mobile technologies in L2 learning can decrease anxiety (i.e., the affective aspect of SRL) for both teachers and learners (Kim, 2018). Others have explored the impact of self-management of learning and personal learning initiative on MALL and highlighted that perceived flexibility in terms of time and place helps learners gain knowledge more easily and conveniently (R. T. Huang \& Yu, 2019).

\section{LA, L2 learning and SRL}

To support L2 learners to develop their ability to regulate their own learning across formal and informal learning environments, LA is critical (Viberg, Khalil, et al., 2020). LA focuses on the improvement of learning outcomes as well as learner support (e.g., for the development of SRL) and teaching (Ferguson \& Clow, 2017). It is understood as "the measurement, collection, analysis and reporting of data about learners in their context, for purposes of understanding and optimising learning and the environments in which it occurs" (Long \& Siemens, 2011, p. 34). LA draws on various academic fields, including education, psychology, pedagogy, statistics, machine learning and computer science (Dawson et al., 2014; Misiejuk \& Wasson, 2017).

Until now, LA has largely been applied in higher education (Viberg, Hatakka, et al., 2018) and often within the context of massive open online courses (e.g., Wong, Baars, et al., 2019), in which considerable amounts of digital learner data are available. The focus on analysing big data to improve learner support and teaching has been also evident among researchers involved in L2 education, including those working with computerassisted language learning (Thomas \& Gelan, 2018). Research attempts in the MALL field have been scarce, with some exceptions (e.g., Chien et al., 2017; Pishtari et al., 2020). 
One of the emerging application areas of LA is SRL, which has been found to be critical for L2 learners (Oxford, 2016). It comprises "the processes whereby students activate and sustain cognitions, affects, and behaviors that are systematically oriented toward the attainment of personal goals" (Schunk \& Zimmerman, 2011, p. 1. Scholars have shown that different LA approaches can be used to measure and support student SRL (Noroozi et al., 2019; Pardo et al., 2017; Tabuenca et al., 2015). However, the results of a recent review of empirical research on SRL and LA in online learning settings highlighted that very limited support has been offered to foster SRL through LA (Viberg, Khalil, et al., 2020).

LA for SRL consists of two mutually constitutive parts: (a) a description of learner SRL activities, based on traces of actions carried out during study (i.e., measurement) and (b) a recommendation, that is, what should be changed about how learning activities are performed) and instructions on how to change them in order to better achieve learning goals (i.e., support; Winne, 2017). SRL requires continuous feedback during the learning process (Schunk \& Greene, 2017; Zimmerman, 2002). The application of LA can aid stakeholders (learners, educators, researchers) in monitoring students' SRL progress. It is also beneficial for helping learners identify and acquire successful learning strategies through relevant support mechanisms. Moreover, the use of LA for SRL can assist learners to motivate themselves through relevant visualisations of their SRL activities (e.g., in the form of open learner models (Bull \& Wasson, 2016)) or learner-facing dashboards (e.g., Davis et al., 2016; Matcha et al., 2019), which in turn can help them plan their next learning steps and progress in their language learning.

A special issue of the journal Computer Assisted Language Learning stressed several themes, including analytics inside and outside language learning, analytics and adaptive language learning, analytics for formative assessments, and stakeholders' readiness to use analytics in teaching and learning an L2 (Thomas \& Gelan, 2018). Scholars have also argued that, by applying LA, learning designers should be able to better meet L2 learners' needs, predict their behaviours and learning outcomes, and provide them with personalised and adaptive learning activities (Lan et al., 2017). Furthermore, researchers have stated that through data visualisations (e.g., student/teacher-facing dashboards of learning activities) L2 learners, educators, and researchers will be better equipped with timely decision-making information to support more successful L2 learning (Viberg, Khalil, et al., 2020).

Despite the fact that some computer-assisted language learning studies have focused on the application of LA to measure different language learning activities, there have been few attempts to offer relevant support mechanisms to educators. Based on an analysis of logged data in an online French course, Youngs et al. (2018) presented visualisations created using data from students' interactions with a course video and its attendant questions. Mouri et al. (2018) proposed and evaluated a visualisation and analysis system for connecting relationships of learning logs, connecting words learned through an e-book to those learned from real life.

The use of mobile technologies is an under-researched area within the LA field (Shorfuzzaman et al., 2019), and scholars have emphasised that there are few studies on data-driven learning with mobile devices in L2 learning research (Pérez-Paredes et al., 2019). This is a critical constraint since extensive earlier research within the MALL field has shown that the use of mobile technologies is advantageous in L2 learning (e.g., Kukulska-Hulme \& Viberg, 2018; Sung et al., 2015). A lack of relevant research targeting LA and MALL is thus a limitation in terms of understanding the transformative nature of language learning as a continuous learning process and providing opportunities to offer relevant feedback and intervene in a timely manner (i.e., being able to optimise student learning and the contexts in which learning occurs). The MALLAS framework addresses LA and MALL by offering insights regarding their potentials and benefits for more effective $\mathrm{L} 2$ acquisition.

\section{Learning design and LA}

There is increasing interest in aligning learning design (LD) and LA (Wasson \& Kirschner, 2020); however, combined efforts in m-learning are rare (Pishtari et al., 2020). LD refers to a sequence of learning tasks, resources, and support that a practitioner develops, which capture the pedagogical intent of a unit of study (Lockyer et al., 2013); specifically, it provides conceptual and methodological tools that assist educators in creating learning environments. LA offers techniques for handling and analysing data that support the decision-making of stakeholders in the learning and/or teaching process. When applied to m-learning, "LD can guide and contextualise the analysis, making them [LA and LD] more meaningful for different 
stakeholders, while LA can contribute to inform design decisions and to evaluate LDs" (Pishtari et al., 2019, p. 1081).

Research on LA in relation to language learning has largely been undertaken in the context of computerassisted language learning (e.g., Thomas \& Gelan, 2018; Yu \& Zhao, 2015), and scholars have primarily applied LA techniques to analyse static learner data, accessible through learning management systems and/or web-based tools. For example, researchers have examined how LD decisions influenced language students' engagement in the virtual learning environment of a distance learning university (Rienties et al., 2018). The results indicate that $55 \%$ of the variance in weekly online engagement in language modules was explained by the way teachers designed the weekly learning activities. Others have investigated which types of learning objects language learners engage with most, aspects of online interaction related to course completion and the most prominent student profiles in the context of a massive open online course on language (Martín-Monje et al., 2018). Short videos were found to be the key learning objects in these types of courses. The regular submission of automatically graded activities was a robust indicator of course completion, and the most prominent student profile was viewers - those who access the learning materials but do not submit work or engage in online interaction actively.

In aligning LA and LD, it is critical to support learning designers, who might also be teachers (Wasson \& Kirschner, 2020). An expert language learning designer needs to make several decisions related to the use of different pedagogies and instructional approaches, digital tools, and learning contexts. This is challenging, as the designer may lack relevant knowledge in one or several areas. Consequently, MALLAS aims to support and inform learning designers in the choices they need to make.

\section{MALL and contextualisation}

Successful MALL experiences will benefit from the careful design and use of L2 learners' contextual information. Context refers to:

Any information that can be used to characterise the situation of an entity. An entity is a person, place, or object that is considered relevant to the interaction between the user [learner] and an application, including the user and applications themselves. (Lincke, 2020, pp. 11-12)

Contextualisation aims to utilise sensors, sensing technologies and information processing techniques to understand the current contextual situation of the user (i.e., the L2 learner) in order to address their specific needs. Most mobile applications lack the ability to capture the users' context or they are limited to the users' current location and time. Furthermore, research has shown that most context-aware m-learning frameworks or models provide personalisation rather than contextualisation for mobile applications (Lincke, 2020).

We argue that contextualisation of self-regulated MALL should consider not only individual learners' preferences but also their learning situations in order to improve their conditions for learning, increase relevance, improve the user experience and decrease routine learner interactions with applications or services. As such, different contextual dimensions (e.g., environment, device, and personal context), relevant mobile sensors (e.g., GPS, camera, accelerometer) and further contextual information (e.g., the type of place where the learner is located, screen size, battery charge level, Internet connectivity, learners' gender, age, and interests) and web services (e.g., Google places API, learning management system web service API) (Lincke, 2020) should be considered. Thus, the main task of contextualisation is to deliver the resource (content, information, or service) that is relevant to the current context of the learner. MALLAS incorporates context in several of its dimensions.

\section{MALLAS conceptual framework}

MALLAS is a conceptual framework that captures the dimensions of SRLL and LA that are required to support MALL. As such, it is an analytical tool that can be used to operationalise the support of MALL in a specific learning context. In this section, we present the framework, and in the next section we describe how MALLAS can be operationalised by learning designers in support of oral language skills. 


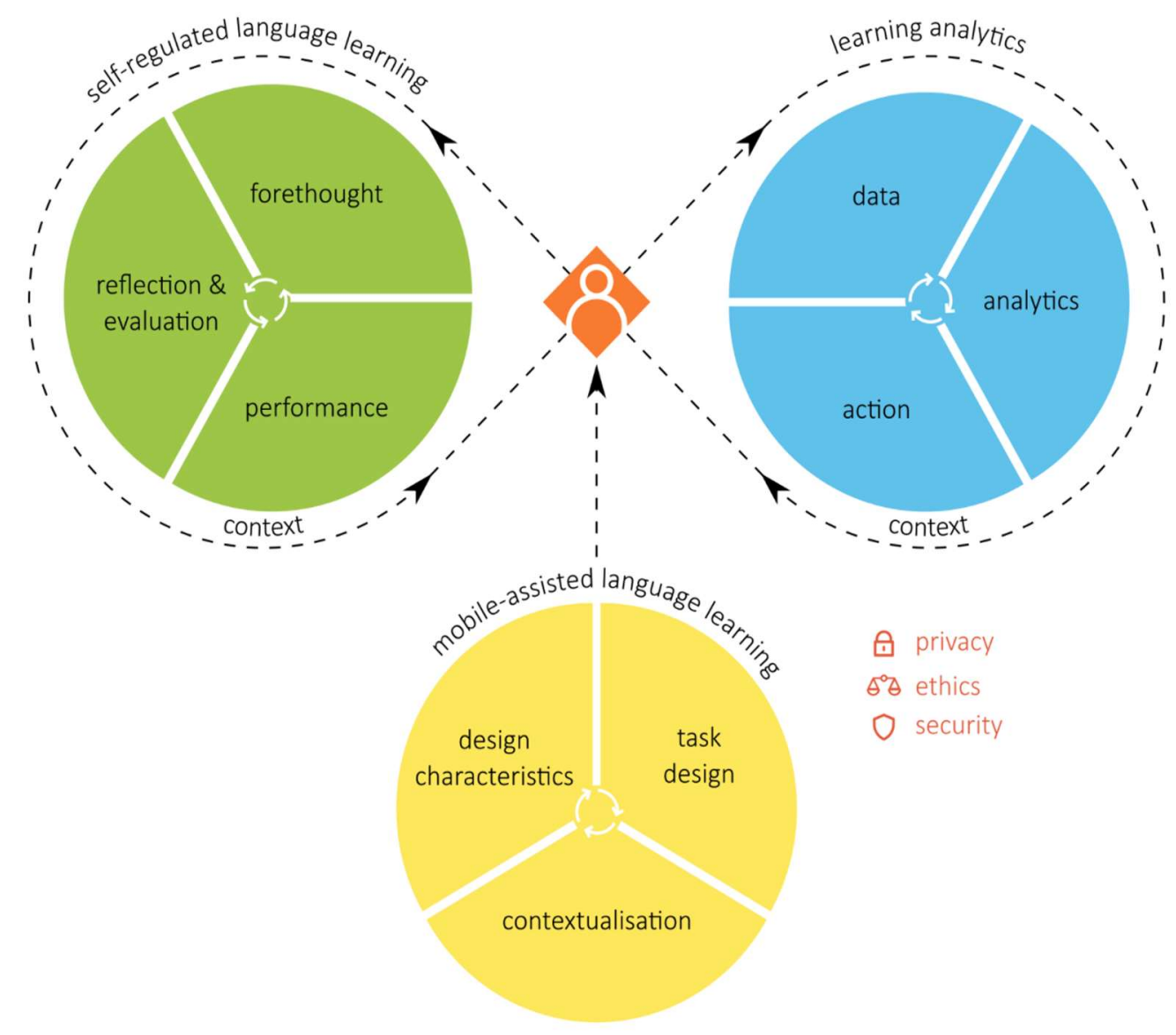

Figure 3. MALLAS

MALLAS (Figure 3) comprises three constitutive parts: MALL, SRLL and LA. The theoretical underpinnings of MALL are described below, followed by SRLL and LA. Through MALLAS, we argue that the L2 learner (middle of Figure 3) will acquire a target language more successfully due to the affordances of MALL, SRLL, and LA in their different combinations, depending on the learner's language learning goals, the learning situation and the learner's context. We suggest MALL will be enhanced by designing relevant support mechanisms, including effective support for the development of the L2 learner SRLL and relevant LA modules aimed at measuring and optimising MALL processes and the environments in which they occur. Such support also needs to develop and integrate relevant mechanisms that protect learner privacy.

\section{MALL}

MALL has three critical aspects: (m-learning) design characteristics, contextualisation and the design of language learning tasks.

\section{Design characteristics}

Since scholars have argued that there are problems with the definition of m-learning, we chose to focus instead on several design characteristics (Grant, 2019). First, the learner is mobile; that is, they move across formal and informal learning environments (online and physical). Second, the learner's device (e.g., smartphone) is mobile, which suggests that support should be developed for use at available and convenient times and places. Third, data services are persistent; that is, applications and services need to be able to store relevant (learner) data and make it available for other services (e.g., LA and recommendations services) and for other users (e.g., to other learners (peer review), educators, and researchers). Fourth, the learning content is mobile; therefore, the content (e.g., text, video) needs to be developed for effective use on a mobile device. Fifth, the learning tutor can be either an educator or an intelligent tutor and needs to be 
accessible to the learner. Earlier research has suggested that this is especially critical during the learner's early stages of developing self-regulation in their learning (Yang, 2020). Sixth, SRL support should engage and support L2 learners in the m-learning process. Seventh, usability and the user experience are important, and MUUX-E (Harpur \& de Villers, 2015), a framework for evaluating usability and user experience in mobile educational contexts, could be employed.

\section{Contextualisation}

Contextualisation of self-regulated MALL builds on the rich context model and contextualisation approach presented by Lincke (2020), which enables not only personalisation but also the provision of the most relevant learning tasks given the learner's current contextual situation. The present context includes not only the location, the time of day, and the learner's needs, interests and preferences (Sotsenko et al., 2014) but also the SRL support they need, their current status with the learning tasks (e.g., what they have completed) and their learning history (with this app or service). Lincke's (2020) model includes an environment context, device context and personal context, and a MALLAS app or service must take these into consideration for both the data collection and recommendation services (Figure 4) that drive the adaptivity or personalisation of the learning app or the service. A MALL context is dependent upon access to relevant mobile sensors (e.g., GPS, camera, accelerometer) to determine contextual information, such as the type of place where the learner is located, screen size, battery charge level, Internet connectivity, and access to stored data to determine learner demographics (e.g., gender, age, interests) if relevant, as well as the status of the learning tasks and SRL needs.

\section{Task design}

In MALLAS, language learning task design is supported by the task phases (i.e., forethought, performance, evaluation and reflection), which are presented in the S2R model (Figure 2), suggesting that the language learning tasks should closely align with these SRL phases. Depending on the specific goals of a proposed MALL activity, language learning tasks can address one or more language skills: speaking, reading, writing or listening, either separately or in combination. They can be various task types (e.g., collaborative, individual, creative with peer feedback), and they can build on the affordances of specific techniques and technologies (e.g., gamification, video-based learning, virtual reality). Furthermore, the design of language learning tasks can draw on different language learning strategies (i.e., cognitive, affective and socioculturalinteractive; Figure 1) and tactics. These strategies and tactics should be employed to support one or several SRLL phases, depending on the individual's preferences, needs and learning progress.

SRL strategies can be taught and learnt (Viberg, Khalil, et al., 2020), which suggests that task design in MALLAS can include specific learning tasks aimed at fostering learners' SRL strategies (e.g., goal-setting or time management) before they are applied to language learning. Task design for MALL includes the design and specification of language learning tasks that require the use of the target language to complete the task and are targeted to a specific learning context, as specified by the contextualisation dimensions. This will enable the MALLAS app or service to recommend a task for a learner based on the current learning context. Task design for MALL should also consider design characteristics (e.g., accessibility of a tutor) and ensure that the proposed tasks are in accordance with them.

\section{SRLL}

SRLL comprises three phases (Zimmerman, 2000) tailored for language learning by Oxford (2016): strategic forethought, strategic performance, and strategic reflection and evaluation. These phases are described from the perspective of supporting the learner, and they are further referred to as forethought, performance, and reflection and evaluation.

\section{Forethought}

In the forethought or planning phase, language learners start by making plans, setting goals, and analysing the task they are planning to perform. For example, a learner planning to spend a certain amount of time studying in order to reach a goal (e.g., to learn different ways of starting a conversation in a target language) and analysing a task (assigned by an instructor or self-initiated), chooses one or several SRL strategies (e.g., communication strategies) to accomplish it. Here, there are several aspects to be considered. In terms of the contextual affordances of MALL, L2 learners should consider the settings in which their goal can be reached most effectively and how a mobile device can be employed to meet this goal. Depending on the context(s), learners will benefit from employing one or several SRL strategies. 
Basing the development of relevant support mechanisms on the theoretical notions of the S2R model (Oxford, 2011, 2016), L2 learners will acquire the target language more effectively through the employment of cognitive, affective, and sociocultural interactive language learning strategies, metastrategies and tactics. Since the learners are frequently unaware of the diverse types and effectiveness of such strategies, these strategies - linked to the development of target language learning skills (e.g., speaking) - can be introduced to the learner. For example, this could be in the form of a specifically designed SRLL module that introduces SRL strategies for the targeted language skills and offers SRL scenarios (both individual and collaborative) to practise the skills, according to the learner's progress, preferences and contextual settings. In order to follow the learner's development of SRL, this module can be made available through special software (e.g., an intelligent tutoring system) on the learner's mobile device(s). The learner will be able to choose one or more strategies (from a list) and practise them according to their preferences, goals and the current learning context.

\section{Performance}

In the performance phase, L2 learners employ chosen and/or recommended strategies, monitor their performance, and control their language learning process. That is, the learner could monitor whether the learning activities undertaken and the SRLL strategies employed are effective in terms of the goals that were set in the planning phase. Based on monitoring processes in the performance phase, the learner could decide to devote more time, use different strategies or to stop studying (i.e., exercise control) because they have reached their goals (Viberg, Khalil, et al., 2020).

In the MALLAS framework, L2 learners should be able to continuously monitor their language learning processes. This will help them to increase their awareness of their SRLL process as a continuous process and progressively adapt language learning to their individual learning progress. The use of the learners' own mobile devices - which should allow them to smoothly bridge their SRLL activities across learning settings - must be carefully considered. LA can support this process by providing relevant information in the form of a learner-facing dashboard. Research has demonstrated that existing support mechanisms for developing student SRL have been limited to web-based visualisation tools (Viberg, Khalil, et al., 2020), in particular web-based learner-facing dashboards (Davis et al., 2016) and intelligent tutoring systems (Azevedo et al., 2019). This has been a serious limitation in terms of learners' ability to continuously monitor their language learning activities across learning settings and, ultimately, to adapt their learning processes based on their individual learning progress.

\section{Reflection and evaluation}

Reflection is an integral part of self-regulation, and it is essential for the metacognitive adaptation of study approaches and goals (Kovanovic et al., 2018). Self-reflection contains "processes that occur after performance efforts and influence a person's response to that experience. These self-reflections, in turn, influence forethought regarding subsequent motoric efforts-thus completing a self-regulatory process" (Zimmerman, 2000, p. 16). That is, in the self-reflection phase, L2 learners assess how they have performed a task, reflecting on their successes and/or failures. These reflections are associated with self-judgement and self-reactions, which can positively or negatively affect how they approach the task in later performances. Self-judgement refers to self-evaluation of one's performance and attributing "casual significance to the results", whereas self-evaluation relates "to comparing self-monitored information with a standard or goal", set in the forethought phase (Zimmerman, 2000, p. 20). Overall, with regard to facilitating L2 learners' L2 acquisition, the early introduction of reflective practice is critical since it will provide them with the opportunity to develop self-regulation and confidence as they set learning goals and take ownership of their learning strategies (Coulson \& Harvey, 2013; Kovanovic et al., 2018). Frequently employed reflection methods include writing reflective journals and producing reflective video annotations (Kovanovic et al., 2018). These methods - linked to the learners' goals and their practice of SRLL strategies - can be developed and integrated into the MALLAS app or service as SRL tasks, monitored through LA and recommended through an intelligent tutor or LA recommendation service.

\section{LA}

LA in MALLAS comprises data, analytics and action (Figure 3), which together are used to measure and support the L2 learner's self-regulated MALL in context. Such support can be offered in the form of relevant visualisations of their learning processes and/or by recommendations of the next language learning task or SRL task with which the learner should engage. 
Data

Data are at the heart of LA. Data can include personal data (e.g., preferences), demographic data (e.g., age), location data (e.g., GPS), activity data (e.g., click stream from using an app) and data about the learning device (e.g., iPhone). This multichannel data is used to understand the learning context (e.g., the learner is outside and moving) and the learning path or process (e.g., the learner has completed all the tasks) and can be used to take action to support learning (e.g., visualisation of what a learner knows and does not know) and to recommend a learning task (e.g., you should revisit your learning goals). The contextualisation of the MALL builds on the rich context model, in which Lincke (2020) groups data into personal, device and environment contexts. LA data will augment the context data already gleaned from the definition of the MALL learning tasks and from the specification of SRL tasks.

Data need to be collected, and the quality of the collected data will have a large impact on the quality of the LA. There are four main factors that will affect the LA quality: richness of the data set; relevance of the data (linked to the posed aims); diversity and quality of the data (e.g., certain multimodal data can be hard to process); and usefulness of the findings generated by (context) analytics (see Lincke, 2020).

Of particular interest in MALLAS is the multichannel learner activity (or process) data derived from the learners' use of the learning app or service on mobile devices, which can be used to enrich analysis techniques. Such process data (e.g., log files, physiological sensor data such as eye movement and spatial data) can be used to build a picture of the SRLL processes learners employ when learning a new language through the use of their mobile devices, in real time. For example, learner activity log file data contain timestamped, behavioural indicators of learners' interactions with a system (e.g., specially developed software for fostering SRLL).

To better understand learners' SRLL processes, we suggest that multichannel data (including self-assessed measurements and various data originating from mobile devices) should be carefully considered by learning designers and researchers, with learner privacy considerations in mind. For example, GPS functions which provide access to learner contextual data - can be used to identify and visualise the contexts in which chosen SRLL strategies work more efficiently (e.g., for some language learners, the use of chosen affective learning strategies could be more efficient in informal learning settings compared to formal educational environments).

Collected data to be used for LA needs to be stored for immediate and latent analysis. Decisions about whether the data should be stored locally on the learning device or in a cloud service need to consider privacy and security issues. Challenges in working with multistream data (i.e., different formats, standards) are also important (Lincke, 2020; Samuelsen et al., 2019).

\begin{abstract}
Analytics
The collected LA data need to be analysed. Mixed-methods analyses - based on the theoretical lens of the S2R model (Oxford, 2016) and the examination of process-oriented behavioural data (e.g., contextual and multimodal data logs), as well as self-assessed generated data (e.g., instruments aiming to measure learners' motivation or level of self-regulation) - will provide a deeper understanding of the complex nature of L2 learners' SRLL processes and further support. To analyse such complex data can be a challenge; most context-aware systems cannot efficiently combine various types of contextual information, and they may suffer from high computational complexity (Lincke, 2020). However, there are examples of quantitative LA methods that can be used. Such methods include process and sequential pattern analysis (e.g., Peeters et al., 2020; Wong, Khalil, et al., 2019). Temporal process mining, stochastic process mining, and epistemic network analysis can be used to unlock temporal patterns of SRL (Saint et al., 2020; Uzir, 2020). To classify learners according to their level of self-regulation in language learning, techniques such as decision trees, neural networks, and network-based diffusion analysis can be used. To better understand the nature of individuals' SRLL processes, we also suggest that more established and validated methods (e.g., surveys and observations) should be considered in combination with quantitative metrics. Data analysis drives the adaptivity of the MALLAS app (i.e., the software-initiated learning activities or behavioural actions) and the visualisations for the learner, educators and researchers (see the Action section).
\end{abstract}

Action

The goal of LA is to optimise learning and the environments in which it occurs (Long \& Siemens, 2011). The results of analytics should be used to assist L2 learners, educators (who teach SRLL strategies) and 
researchers (who help to develop relevant support tools). For learners, we suggest that the acquisition of the target L2 will be facilitated by the development and use of interactive visualisations (accessible through their mobile devices) of learners' choices (goals and selected SRLL strategies).

The results of relevant analyses should also be used to provide appropriate support for teachers, for example, through the development of a teacher-facing dashboard that will visualise students' SRL processes, both on the individual and/or group level over time. This dashboard will assist them not only in their understanding of students' invisible SRLL processes but also in informing the design of relevant teaching activities to further foster students' SRL in educational settings and provide them with adequate support. For example, if the teacher sees that the use of the strategies chosen by the learner does not help them to progress in the development of their speaking skills, the teacher can recommend another set of strategies.

To assist researchers to trace L2 learners' SRLL activities through a process-oriented approach, we suggest the development of a graphical user interface that can facilitate data visualisation and processing - hence providing novel opportunities for researchers to travel through the rich learner data and its characteristics. This will contribute to a deeper understanding of the underexplored role of self-regulation in the MALL research field (Viberg \& Andersson, 2019), further theoretical development of the SRL research area (Noroozi et al., 2019), and, finally, the development of adequate LA support for SRL (Viberg, Khalil, et al., 2020).

\section{Privacy, security and ethics}

There are several privacy, ethical and security constraints that should be considered within the frame of MALLAS. They relate to two key aspects. First, there are several constraints linked to LA research in three overlapping categories: location and interpretation of data; informed consent, privacy and the deidentification of data; and management, classification and storage of data (Slade \& Prinsloo, 2013). These constraints include issues of transparency, accessibility, security, ownership, policy, accuracy and privacy (Khalil \& Ebner, 2015). Second, it is important to consider that the mobile devices used by learners are personal tools on which the learners often store private information, which creates additional challenges and potential risks to learners' security and privacy. To enable responsible use of LA in the MALL area, it is crucial to protect learner privacy and security in each case in relation to the sociocultural setting and existing policies. Many institutions, however, still lack relevant policy documents. One way to start would be to follow current national and international frameworks, such as the General Data Protection Regulation (in Europe; European Union, n.d.) and the Family Educational Rights and Privacy Act (in the United States of America; U.S. Department of Education, 2018). Furthermore, following the recommendations for privacy and data protection in mobile applications provided by the European Union Agency for Network and Information Security (2017), the designers of mobile applications should address core data protection principles related to lawfulness, fairness, and transparency; purpose limitation; data minimisation; accuracy; storage limitation; and integrity and confidentiality (p. 17). Overall, we argue that the protection of L2 learner privacy is both a moral and a legal obligation. Learner privacy is more than just data collection and legal protections; it is about real individuals and their agency. Privacy is not only a right to control access to and use information but also a human right, where learner "data protection is not only a fundamental right among others but the most expressive of the contemporary human condition" (Rodotà, 2009, p. 82).

\section{Operationalisation of MALLAS}

To illustrate the usefulness of MALLAS, we describe its operationalisation by a learning designer hired by an institution to make the specifications for a MALL app or service for L2 learners aiming to enhance their L2 speaking skills. Figure 4 illustrates a scenario where a learning designer, informed by the framework, specifies the requirements for a MALLAS app or service developer and offers guidelines to a teacher, who will design oral communication learning tasks. Oral competence is often mentioned as an area of weakness among language learners (Tabassum \& Hossain, 2020), yet it is required in most occupations and identified by employers as vital for successful job performance (Aichhorn \& Puck, 2017). Oral communication can be a performance or an act of social interaction that requires an understanding of sociocultural usage norms and appropriate use in a given context (Savignon, 2018). Communicative competence comprises listening comprehension and conversation skills (McGroarty, 1984). Communication strategies focus on managing communication problems, for example, via paraphrasing, comprehension checks, appeals for assistance 
(Dörnyei \& Scott, 2002), socio-affective strategies (e.g., managing anxiety) and ways to enhance communication through politeness or hedging.

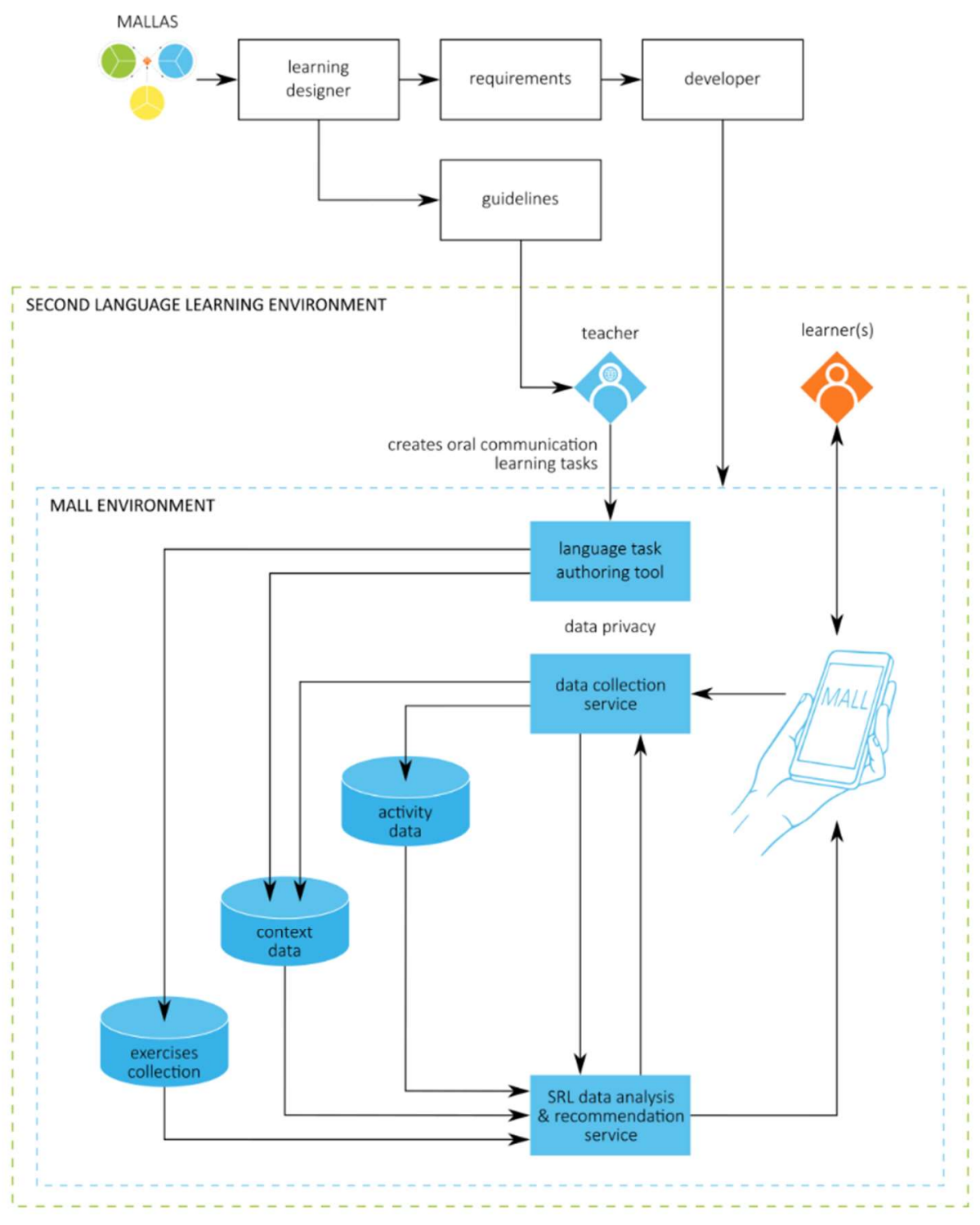

Figure 4. Operationalisation of the MALLAS framework

MALLAS guides the learning designer to consider several design characteristics: the learner is mobile, the learner's device is mobile, data services are persistent and the learning content is mobile. These characteristics will impact the guidelines for teachers and the requirements for a MALL app or service developer.

\section{Guidelines for teachers}

Task design guidelines build on the fact that the learner, the learner device, and the learning content are mobile. This means that the learning designer needs to create guidelines that will aid teachers in creating relevant learning and SRL tasks (the learning designer might create the SRL tasks). 
The learning designer can provide the following guidelines to the teacher:

- Develop oral learning tasks; for example, address engaging in a conversation (starting a conversation, maintaining it, changing topics, ending the conversation) to support learners' specific goals at work or in other settings.

- Develop SRL tasks to support oral language development.

- Consider 12 task type designs (e.g., collaborative, creative tasks with peer feedback) and specific 12 communication strategies (including reflection on current helpful and less helpful strategies and instruction on new strategies to test).

- The learning tasks should take advantage of the learner's current learning situation (i.e., context); for example, if on the bus or metro, listen to the announcement of the next stop and see if you have understood correctly.

- Design supporting learning materials in several modalities (e.g., to be read, or listened to).

- Design tasks that can be carried out in different ways (e.g., writing, if on a tablet; recording, if on a smartphone; taking a picture, if a smartphone or tablet is available).

- Content (e.g., text, video, and music) needs to be suitable for effective use on a learner's mobile device.

Requirements for MALL app or service development

The learning designer provides requirements for the MALL app or service. Here, we provide fairly general requirements (just to give a flavour of what kind of specifications are needed).

The MALL app or service:

- $\quad$ needs to be available for both Android and iOS

- can be used both individually and collaboratively

- $\quad$ needs to provide a language or SRL task authoring tool for teachers or the learning designer and collect the designed tasks

- needs to be adaptive to the learner context (e.g., device characteristics, location, learner preferences)

- $\quad$ needs to provide feedback to teachers and learners

- needs to allow user or system control (e.g., choice of next task)

- $\quad$ needs to meet security and privacy regulations.

SRL support needs to provide:

- $\quad$ SRL activities (aiming at fostering, for example, goal-setting)

- teacher- and/or learner-facing dashboards tailored to support SRLL

- feedback

- recommendations.

The requirements for LA are:

- Activity data need to be collected.

- Context data need to be collected.

- A data service needs to be persistent.

- A model of learner characteristics, including background and preferences, needs to be built.

- Data analytics are needed to maintain the learner model and dashboards.

- Rules for a recommender algorithm to determine the relevance of the task modality and task ordering, considering location context data need to be developed.

- The app should learn across learners' data.

- Analytics for dashboard visualisations need to be developed and implemented. 


\section{Conclusion}

This paper offers a conceptual framework, MALLAS, to support L2 learners through LA for SRL across learning environments. MALLAS builds on contemporary research within mobile language learning, LA and SRL. MALLAS is largely aimed at learning designers of MALL solutions. The learning designer can use MALLAS as a guide to direct design choices related to the development of MALL apps and services to be used either in educational or non-educational settings. Moreover, the learning designer can offer relevant guidelines to the teacher to facilitate students' L2 acquisition while simultaneously fostering their SRL (i.e., a transferable lifelong learning skill that can support learners in other studies and work). The learning designer also provides requirements for a MALL app or service to be implemented by developers.

Although MALLAS is aimed mainly at learning designers, it is equally of interest to researchers who want to better understand and support SRLL in m-learning contexts. For researchers, MALLAS can guide the planning of research studies as well as its use to trace, interpret and evaluate students' SRLL activities through a process-oriented approach - as opposed to measuring SRLL as a static process. The SRLL activities can be made visible not only to researchers but also to learners (to improve their ability to selfregulate their learning) and to teachers (to aid them in intervening in a timely manner and teaching relevant SRLL strategies).

The types of data that can be collected for LA will vary in each case and depend on various factors, including the extent to which researchers consider the selected contextual information, learner mobility, and specific technologies. Consequently, analyses of these data will provide valuable insights into learners' previously largely invisible SRLL activities and processes across learning contexts.

Although the m-learning analytics field can be perceived as challenging, it is also promising for practitioners and researchers because of the unique features provided through mobile devices. That is, by carefully designing MALL activities and taking advantage of mobile device or service features, there is an opportunity to collect rich, multifaceted, process-oriented learner data (including temporal multimodal and contextual data) to examine and to visualise learners' cognitive, affective and sociocultural-interactive SRL processes while acquiring the target language.

Recently, LA research examining the temporal nature of students' SRL processes has shown some positive evidence in this regard (e.g., Saint et al., 2020; Uzir, 2020). However, current LA analyses are largely based on the examination of students' log data from learning management systems, which provide a limiting view of individuals' SRL. Azevedo and Gasevic (2019) stressed that "analyses of multimodal multichannel SRL process data can significantly augment advanced learning technologies by providing real-time, intelligent, adaptive, individualised scaffolding and feedback to address learners' self-regulatory needs" (p. 207). MALLAS takes a step in this direction by aiding in the design of self-regulated adaptive MALL.

\section{References}

Aichhorn, N., \& Puck, J. (2017). “I just don’t feel comfortable speaking English": Foreign language anxiety as a catalyst for spoken-language barriers in MNCs. International Business Review, 26(4), 749-763. https://doi.org/10.1016/j.ibusrev.2017.01.004

Azevedo, R., \& Gasevic, D. (2019). Analyzing multimodal multichannel data about self-regulated learning with advanced learning technologies. Issues and challenges. Computers in Human Behavior, 96, 207-210. https://doi.org/10.1016/j.chb.2019.03.025

Azevedo, R., Mudrick, N., Taub, M., \& Bradbury, A. (2019). Self-regulation in computer-assisted learning systems. In J. Dunlosky \& K. Rawson (Eds.), The Cambridge handbook of cognition and education (pp. 587-618). Cambridge University Press. https://doi.org/10.1017/9781108235631.024

Baars, M., Leopold, C., \& Paas, F. (2018). Self-explaining steps in problem-solving tasks to improve selfregulation in secondary education. Journal of Educational Psychology, 110, 578-595. https://doi.org/10.1037/edu0000223

Bull, S., \& Wasson, B. (2016). Competence visualisation: Making sense of data from 21 st century technologies in language learning. RECALL, 28(2),147-165.

https://doi.org/10.1017/S0958344015000282 
Chien, T.-C., Chen, Z.-H., \& Chan, T.-W. (2017). Exploring long-term behavior patterns in a book recommendation system for reading. Educational Technology \& Society, 20(2), 27-36. https://drive.google.com/file/d/1QCq6JTLuRWe-keKN2SO7t3Zv3ZP X81V/view

Coulson, D., \& Harvey, M. (2013). Scaffolding student reflection for experience-based learning: A framework. Teaching in Higher Education, 18(4), 401-413. https://doi.org/10.1080/13562517.2012.752726

Crompton, H. (2013). A historical overview of m-learning: Toward learner-centered education. In Z. L. Berge \& L. Y. Muilenburg (Eds.), Handbook of mobile learning (pp. 3-14). Routledge. https://doi.org/10.4324/9780203118764.ch1

Davis, D., Chen, G., Jivet, I., Hauff, C., \& Houben, G. (2016). Encouraging metacognition and selfregulation in MOOCs through increased learner feedback. In S. Bull, B. M. Ginon, J. Kay, M. D. Kickmeier-Rust, \& M. D. Johnson (Eds.), Proceedings of the LAK 2016 Workshop on Learning Analytics for Learners (Vol. 1596, pp. 17-22). CEUR-WS. http://ceur-ws.org/Vol-1596/paper3.pdf

Dawson, S., Gasevic, D., Siemens, G., \& Joksimovic, S. (2014). Current state and future trends: A citation network analysis of the learning analytics field. In Proceedings of the Fourth International Conference on Learning Analytics \& Knowledge (pp. 231-240). Association of Computing Machinery. https://doi.org/10.1145/2567574.2567585

Di Carlo, S. (2016). The use of learning strategies among learners of Spanish: An empirical study. Porta Linguarum, 26, 81-92. https://www.ugr.es/ portalin/articulos/PL_numero26/ART6_Sergio\%20di\%20Carlo.pdf

Dörnyei, Z., \& Scott, M. L. (2002). Communication strategies in a second language: Definitions and taxonomies. Language Learning, 47(1), 173-210. https://doi.org/10.1111/0023-8333.51997005

Dunlosky, J., \& Lipko, A. (2007). Metacomprehension: A brief history and how to improve its accuracy. Current Directions in Psychological Science, 16(4), 228-232. https://doi.org/10.1111/j.1467$\underline{\text { 8721.2007.00509.x }}$

European Union. (n.d.). EU data protection rules. https://ec.europa.eu/info/law/law-topic/dataprotection/eu-data-protection-rules_en

European Union Agency for Network and Information Security. (2017). Privacy and data protection in mobile applications: A study on the app development ecosystem and the technical implementation of GDPR. https://doi.org/10.2824/114584

Ferguson, R., \& Clow, D. (2017). Where is the evidence? A call to action for learning analytics. In Proceedings of the Seventh International Learning Analytics \& Knowledge Conference (pp. 56-65). Association for Computing Machinery. https://doi.org/10.1145/3027385.3027396

Grant, M. (2019). Difficulties in defining mobile learning: Analysis, design characteristics, and implications. Educational Technology Research and Development, 67(2), 361-388. https://doi.org/10.1007/s11423-018-09641-4

Harpur, R., \& de Villiers, R. (2015). MUUX-E, a framework of criteria for evaluating the usability, user experience and educational features of m-learning environments. South African Computer Journal, 56, 1-21. https://doi.org/10.18489/sacj.v56i1.240

Huang, C., Yang, S., Chiang, T., \& Su, A. (2016). Effects of situated mobile learning approach on learning motivation and performance of EFL students. Educational Technology \& Society, 19(1), 263-276. https://www.jstor.org/stable/jeductechsoci.19.1.263

Huang, R.-T., \& Yu, C.-Y. (2019). Exploring the impact of self-management of learning and personal learning initiative on mobile language learning: A moderated mediation model. Australasian Journal of Educational Technology, 35(3), 118-131. https://doi.org/10.14742/ajet.4188

Khalil, M., \& Ebner, M. (2015). Learning analytics: Principles and constraints. In S. Carliner, C. Fulford, \& N. Ostashewski (Eds.), Proceedings of the World Conference on Educational Media and Technology (pp. 1789-1799). AACE. https://www.learntechlib.org/p/151455/

Kim, Y. (2018). The effects of mobile-assisted language learning (MALL) on Korean college students' English-listening performance and English-listening anxiety. In Proceedings of the 8th International Conference on Languages, Social Sciences, Education and Interdisciplinary Studies (pp. 277-298). Higher Education and Innovation Group. https://doi.org/10.15242/HEAIG.H1217424

Köksal, D., \& Dundar, S. (2018). Öz-Düzenlemeli Yabancı Dil Öğrenme Strateji Kullanımı Ölçeği'nin Geliştirilmesi (Developing a scale for self-regulated L2 learning strategy use). Hacettepe Üniversitesi Ĕ̌itim Fakültesi Dergisi, 33(2), 337-352. https://doi.org/10.16986/HUJE.2017033805 
Kovanovic, V., Joksimovic, S., Mirriahi, N., Blaine, E., Gasevic, D., \& Siemens, G., \& Dawson, S. (2018). Understand students' self-reflections through learning analytics. In S. Buckingham Shum, Ferguson, R., Merceron, A., \& Ochoa, X. (Eds), Proceedings of the 8th International Conference on Learning Analytics and Knowledge Management (pp. 389-398). Association for Computing Machinery. https://doi.org/10.1145/3170358.3170374

Kukulska-Hulme, A., \& Bull, S. (2008). Theoretical perspectives on mobile language learning diaries and noticing for learners, teachers and researchers. In J. Traxler, B., Riordan, \& C. Dennett (Eds.), Proceedings of the mLearn 2008 Conference (pp. 184-192). International Association for Mobile Learning. https://iamlearn.org/wp-content/uploads/2018/01/mlearn2008_proceedings.pdf

Kukulska-Hulme, A., \& Viberg, O. (2018). Mobile collaborative language learning: State of the art. British Journal of Educational Technology, 49(2), 207-218. https://doi.org/10.1111/bjet.12580

Lan, Y.-J., Chen, N. S., \& Sung, Y.-T. (2017). Learning analytics in technology enhanced language learning [Editorial]. Educational Technology \& Society, 20(2), 158-160.

Lincke, A. (2020). A computational approach for modelling context across different application domains [Doctoral thesis, Linnaeus University]. DiVA. http://www.divaportal.org/smash/record.jsf?pid=diva2 $\% 3 \mathrm{~A} 1421481 \& \mathrm{dswid}=59$

Lockyer, L., Heathcote, E., \& Dawson, S. (2013). Informing pedagogical action: Aligning learning analytics with learning design. American Behavioral Scientist, 57(10), 1439-1459. https://doi.org/10.1177/0002764213479367

Lodge, J., Panadero, E., Broadbent, J., \& de Barba, P. (2018). Supporting self-regulated learning with learning analytics. In J. Lodge, J. C. Horvath \& L. Corrin (Eds.), Learning analytics in the classroom (1st ed., pp. 45-55). Routledge. https://doi.org/10.4324/9781351113038-4

Long, P., \& Siemens, G. (2011). Penetrating the fog: Analytics in learning and education. Educause Review, 46(5), 31-40. https://er.educause.edu/articles/2011/9/penetrating-the-fog-analytics-inlearning-and-education

Martín-Monje, E., Dolores Castrillo, M., \& Mañana-Rodríguez, J. (2018). Understanding online interaction in language MOOCs through learning analytics. Computer Assisted Language Learning, 31(3), 251-272. https://doi.org/10.1080/09588221.2017.1378237

Matcha, W., Uzir, N., Gasevic, D., \& Pardo, A. (2019). A systematic review of empirical studies on learning analytics dashboards: A self-regulated learning perspective. IEEE Transactions on Learning Technologies, 13(2), 226-245. https://doi.org/10.1109/TLT.2019.2916802

McGroarty, M. (1984). Some meanings of communicative competence for second language students. TESOL Quarterly, 18(2), 257-272. https://doi.org/10.2307/3586693

Misiejuk, K. \& Wasson, B. (2017). State of the field report on learning analytics (SLATE Report 20172). University of Bergen. http://hdl.handle.net/1956/17740

Mouri, K., Uosaki, N., \& Ogata, H. (2018). Learning analytics for supporting seamless language learning using e-book with ubiquitous learning system. Journal of Educational Technology \& Society, 21(2), 150-163. https://www.jstor.org/stable/26388390

Noroozi, O., Alikhani, I., Järvelä, S., Kirschner, P., Juuso, I., \& Seppänen, T. (2019). Multimodal data to design visual learning analytics for understanding regulation of learning. Computers in Human Behavior, 100, 298-304. https://doi.org/10.1016/j.chb.2018.12.019

Oxford, R. (2011). Teaching and researching language learning strategies. Pearson Education Limited.

Oxford, R. (2016). Teaching and researching language learning strategies: Self-regulation in context (2nd ed). Routledge.

Palalas, A., \& Hoven, D. (2016). Emerging pedagogies for MALL. In A. Palalas \& M. Ally (Eds.), The international handbook of mobile-assisted language learning (pp. 44-85). China Central Radio \& TV University Press.

Panadero, E. (2017). A review of self-regulated learning: Six models and four directions for research. Frontiers in Psychology, 8(422), 1-28. https://doi.org/10.3389/fpsyg.2017.00422

Pardo, A., Han, F., \& Ellis, R. (2017). Combining university student self-regulated learning indicators and engagement with online learning events to predict academic performance. IEEE Transactions on Learning Technologies, 10(1), 82-92. https://doi.org/10.1109/TLT.2016.2639508

Peeters, W., Saqr, M., \& Viberg, O. (2020). Applying learning analytics to map students' self-regulated learning tactics in an academic writing course. In H.-J. So, M. M. Rodrigo, J. Mason, \& A. Mitrovic (Eds.), Proceedings of the 28th International Conference on Computers in Education (Vol. 1, pp. 245-254). Asia-Pacific Society for Computers in Education. https://apsce.net/upfile/icce2020/ICCE\%202020\%20Proceedings\%20-\%20Volume\%20I\%20v4.pdf 
Pérez-Paredes, P., Ordoñana Guillamón, C., Van de Vyver, J., Meurice, A., Aguado Jiménez, P., Conole, G., \& Sánchez Hernández, P. (2019). Mobile data-driven language learning: Affordances and learners' perception, System, 84, 145-159. https://doi.org/10.1016/j.system.2019.06.009

Pishtari, F., Rodriguez-Triana, M., Sarmiento-Marques, E., Perez-Sanagustin, M., Ruiz-Calleja, A., Santos, P., Prieto, L., Serrano-Iglesias, S., \& Väljataga, T. (2020). Learning design and learning analytics in mobile and ubiquitous learning: A systematic review. British Journal of Educational Technology, 51(4), 1078-1100. https://doi.org/10.1111/bjet.12944

Rienties, B., Lewis, T., McFarlane, R., Nguyen, Q., \& Toetenel, L. (2018). Analytics in online and offline learning environments: the role of learning design to understand student online engagement. Computer Assisted Language Learning, 31(3), 273-293. https://doi.org/10.1080/09588221.2017.1401548

Rodotà, S. (2009). Data protection as a fundamental right. In S. Gutwirth, Y. Poullet, P. De Hert, C. de Terwangne, \& S. Nouwt (Eds.), Reinventing data protection? (pp. 77-82). Springer. https://doi.org/10.1007/978-1-4020-9498-9_3

Rubin, J. (2011). Language learner self-management. Journal of Asian Pacific Communications, 11, 2537. https://doi.org/10.1075/japc.11.1.05rub

Saint, J., Gasevic, D., Matcha, W., Uzir, N., \& Pardo, A. (2020). Combining analytics methods to unlock sequential and temporal patterns of self-regulated learning. In C. Rensing \& H. Drachsler (Eds.), Proceedings of the Tenth Conference on Learning Analytics and Knowledge (pp. 402-411). Association for Computing Machinery. https://doi.org/10.1145/3375462.3375487

Samuelsen, J., Chen, W. \& Wasson, B. (2019). Integrating multiple data sources for learning analyticsReview of literature. Research and Practice in Technology Enhanced Learning, 14, Article11). https://doi.org/10.1186/s41039-019-0105-4

Savignon, S. J. (2018). Communicative competence. In J. Liontas (Ed.), The TESOL Encyclopedia of English language teaching (pp. 1-7). Wiley. https://doi.org/10.1002/9781118784235.eelt0047

Scarcella, R. C., \& Oxford, R. L. (1992). The tapestry of language learning: The individual in the communicative classroom. Heinle \& Heinle. https://doi.org10.1017/S0272263100012663

Shadiev, R., Liu, T., \& Hwang, W.-Y., (2019). Review of research on mobile-assisted language learning in familiar, authentic environments. British Journal of Educational Technology, 51(3), 709-720. https://doi.org/10.1111/bjet.12839

Schunk, D. \& Greene, J. (2018). Handbook of self-regulation and learning performance (2nd ed.). Routledge.

Schunk, D. H., \& Zimmerman, B. (Eds.). (2011). Handbook of self-regulation of learning and performance (1st ed.). Routledge. https://doi.org/10.4324/9780203839010

Shorfuzzaman, M., Hossain, M. S., Nazir, A., Muhammad, G., \& Alamri, A. (2019). Harnessing the power of big data analytics in the cloud to support learning analytics in mobile learning environment. Computers in Human Behavior, 92, 578-588. https://doi.org/10.1016/j.chb.2018.07.002

Slade, S., \& Prinsloo, P. (2013). Learning analytics: ethical issues and dilemmas. American Behavioral Scientist, 57(10), 1509-1528. https://doi.org/10.1177/0002764213479366

Sotsenko, A., Jansen, M. \& Milrad, M. (2014). Implementing and validating a mobile learning scenario using contextualised learning objects. In C.C. Liu et al. (Eds.), Proceedings of the 22nd International Conference on Computers in Education (pp. 522-527). Asia-Pacific Society for Computers in Education.

Sung, Y.-T., Chang, K.-E., \& Yang, J.-M. (2015). How effective are mobile devices for language learning: A meta-analysis. Educational Research Review, 16, 68-84. https://doi.org/10.1016/j.edurev.2015.09.001

Tabassum, M., \& Hossain, M. (2020). Oral communication apprehension (OCA) among undergraduate accounting and journalism students in Bangladesh. International Journal of Linguistics, Literature and Translation, 3(1), 176-186. https://doi.org/10.2139/ssrn.3528396

Tabuenca, B., Kalz, M., Drachsler, H., \& Specht, M. (2015). Time will tell: The role of mobile learning analytics in self-regulated learning. Computers \& Education, 89, 53-74. https://doi.org/10.1016/j.compedu.2015.08.004

Thomas, M., \& Gelan, A. (2018). Special edition on language learning and learning analytics. Computer Assisted Language Learning, 31(3), 181-184. https://doi.org/10.1080/09588221.2018.1447723

Traxler, J., \& Kukulska-Hulme, A. (Eds). (2016). Mobile learning: The next generation. Routledge.

Uebelmesser, S., \& Weingarten, S. (2017). A macro-level analysis of adult-age language learning (Working Paper, No. 6511). Center for Economic Studies and Ifo Institute (CESifo).

https://ideas.repec.org/p/ces/ceswps/ 6511.html 
UNESCO. (2012). UNESCO guidelines for the recognition, validation and accreditation of the outcomes of non-formal and informal learning. http://unesdoc.unesco.org/images/0021/002163/216360e.pdf

U.S. Department of Education. (2018). Family Educational Rights and Privacy Act (FERPA). https://www2.ed.gov/policy/gen/guid/fpco/ferpa/index.html

Uzir, N. (2020). Analytics of time management strategies in online learning environments: A novel methodological approach [Unpublished $\mathrm{PhD}$ dissertation]. University of Edinburgh.

Viberg, O., \& Andersson, A. (2019). The role of self-regulation and structuration in mobile learning. International Journal of Mobile and Blended Learning, 11(4), 42-58. https://doi.org/10.4018/IJMBL.2019100104

Viberg, O., Andersson, A., \& Wiklund, M. (2018). Designing for sustainable mobile learning: Re-evaluating the concepts 'formal' and 'informal.' Interactive Learning Environments. https://doi.org/10.1080/10494820.2018.1548488

Viberg, O., Hatakka, M., Bälter, O., \& Mavroudi, A. (2018). The current landscape of learning analytics in higher education. Computers in Human Behavior, 89, 98-110. https://doi.org/10.1016/j.chb.2018.07.027

Viberg, O., Khalil, M., \& Baars, M. (2020). Self-regulated learning and learning analytics in online learning environments: A review of empirical research. In C. Rensing \& Drachsler, H. (Eds.), Proceedings of the Tenth Conference on Learning Analytics and Knowledge (pp. 524-533). Association for Computing Machinery. htttps://doi.org/10.1145/3375462.3375483

Viberg, O., Mavroudi A., \& Ma, Y. (2020). Supporting second language learners' development of affective self-regulated learning skills through the use and design of mobile technology. In C. Alario-Hoyos, M. Rodríguez-Triana, M. Scheffel, I. Arnedillo-Sánchez, \& S. Dennerlein (Eds.), Addressing global challenges and quality education: Proceedings of the 15th European Conference on Technology Enhanced Learning (pp. 173-186). Springer. https://doi.org/10.1007/978-3-030-57717-9_13

Vogel, D., Kennedy, D., \& Kwok, R. C.-W. (2009). Does using mobile devices application lead to learning? Journal of Interactive Learning Research, 20(4), 469-485. https://www.learntechlib.org/primary/p/29431/

Wasson, B., \& Kirschner, P. (2020). Learning design: European approaches. TechTrends, 64, 815-822. https://doi.org/10.1007/s11528-020-00498-0

Winne, P. (2017). Learning analytics for self-regulated learning. In C. Lang, G. Siemens, A. Wise, \& D. Gašević (Eds.), Handbook of learning analytics (pp. 241-249). https://doi.org/10.18608/hla17.021

Wong, J., Baars, M., Davis, D., Van Der Zee, Houben, G.-J., \& Paas, F. (2019). Supporting self-regulated learning in online learning environments and MOOCs: A systematic review. International Journal of Human-Computer Interaction, 35(4-5), 256-373. https://doi.org/10.1080/10447318.2018.1543084

Wong, J., Khalil, M., Baars, M., de Koning, B. B., \& Paas, F. (2019). Exploring sequences of learner activities in relation to self-regulated learning in a massive open online course. Computers \& Education, Article 103595. https://doi.org/10.1016/j.compedu.2019.103595

Yang, Z. (2020). A study of self-efficacy and its role in mobile-assisted language learning. Theory and Practice in Language Studies, 10(4), 439-444. http://www.academypublication.com/ojs/index.php/tpls/article/view/tpls1004439444

Youngs, B., Prakash, A., \& Nugent, R. (2018). Statistically-driven visualizations of student interactions with a French online course. Computer Assisted Language Learning, 31(3), 206-225. https://doi.org/10.1080/09588221.2017.1367311

$\mathrm{Yu}, \mathrm{L}$. (2015). Effects of intervention on self-regulated learning for second language learners [Doctoral dissertation, University of Arkansas]. ScholarWorks@UARK. https://scholarworks.uark.edu/cgi/viewcontent.cgi?article $=2228 \&$ context $=$ etd

$\mathrm{Yu}, \mathrm{Q}$., \& Zhao, Y. (2015). The value and practice of learning analytics in computer assisted language learning. Studies in Literature and Language, 10(2), 90-96. http://www.cscanada.net/index.php/sll/article/view/6529

Zimmerman, B. (1990). Self-regulated learning and academic achievement: An overview. Educational Psychologist, 25(1), 3-17. https://doi.org/10.1207/s15326985ep2501_2

Zimmerman, B. J. (2000). Attaining self-regulation: A social cognitive perspective. In M. Boekaerts, P. R. Pintrich, \& M. Zeidner (Eds.), Handbook of self-regulation (pp. 13-39). Academic Press. https://doi.org/10.1016/B978-012109890-2/50031-7

Zimmerman, B. (2002). Becoming a self-regulated learner: An overview. Theory into Practice, 41(2), 64-70. https://doi.org/10.1207/s15430421tip4102_2 
Corresponding author: Olga Viberg, oviberg@kth.se

Copyright: Articles published in the Australasian Journal of Educational Technology (AJET) are available under Creative Commons Attribution Non-Commercial No Derivatives Licence (CC BY-NC-ND 4.0). Authors retain copyright in their work and grant AJET right of first publication under CC BY-NC-ND 4.0 .

Please cite as: Viberg, O., Wasson, \& Kukulska-Hulme, A. (2020). Mobile-assisted language learning through learning analytics for self-regulated learning (MALLAS): A conceptual framework.

Australasian Journal of Educational Technology, 36(6), 34-52. https://doi.org/10.14742/ajet.6494 